TE DEUM: Jurnal Teologi dan Pengembangan Pelayanan

Volume 10, Nomor 2 (Juni 2021): 205-226

ISSN 2252-3871 (print), 2746-7619 (online)

http://ojs.sttsappi.ac.id/index.php/tedeum/index

DOI: https://doi.org/10.51828/td.v10i2.38

\begin{tabular}{|l|l|l|}
\hline Submitted: 23-2-2021 & Accepted: 9-6-2021 & Published: 25-6-2021
\end{tabular}

\title{
MAKNA “INJIL YANG LAIN” DALAM GALATIA 1:6-7
}

\section{Robi Prianto ${ }^{1}$, Kezia Lawira ${ }^{2}$, Novianto 3}

Sekolah Tinggi Teologi Studi Alkitab Untuk Pengembangan Pedesaan

Indonesia (ST'T SAPPI) Ciranjang ${ }^{12} 3$

rpkgtloh@gmail.com; k3z1alawira@yahoo.com; antokodrat9@gmail.com

\section{ABSTRACT}

The Gospel is the Good News from God about Christ. A message about salvation that is not from God cannot be called the Gospel. Paul in Galatians 1:6-7 rebukes the Galatians for switching from the gospel to a different teaching of salvation, which Paul calls "another gospel". This article examines what is meant by "another gospel" in Galatians 1:6-7. Through the historical-grammatical research method, the writer finds that the "another gospel" that Paul refers to is a teaching that adds culture as an obligation that Christians must do to obtain perfect salvation.

Keywords: Gospel, grace, heresies, Galatians, culture.

\section{ABSTRAK}

Injil adalah Kabar Baik dari Allah tentang Kristus. Berita mengenai keselamatan yang bukan dari Allah tidak bisa disebut sebagai Injil. Paulus dalam Galatia 1:6-7 menegur jemaat Galatia karena telah beralih dari Injil kepada suatu ajaran keselamatan yang lain yang Paulus sebut sebagai "injil yang lain". Artikel ini meneliti apa yang dimaksud mengenai "Injil yang lain" dalam Galatia 1:6-7. Melalui metode penelitian historis-gramatikal, penulis menemukan bahwa "Injil yang lain" yang dimaksud oleh Paulus adalah suatu ajaran yang menambahkan budaya sebagai suatu kewajiban yang harus dilakukan orang Kristen untuk memperoleh keselamatan yang sempurna.

Kata-kata kunci: Injil, kasih karunia, ajaran sesat, surat Galatia, budaya. 


\section{PENDAHULUAN}

Orang Kristen di Galatia sedang mengalami goncangan mengenai iman mereka kepada Yesus Kristus. Hal itu disebabkan oleh adanya pengaruh dari orang Kristen yang berlatar belakang Yahudi yang datang dari Yerusalem, dimana mereka memberitakan bahwa untuk memperoleh pembenaran, tidak cukup dengan beriman saja, namun, harus ditambahkan dengan menaati Injil yang lain.

Tujuan penulisan artikel ini adalah meneliti makna frasa "Injil yang lain" dalam Galatia 1:6-7. Limbaugh menjelaskan bahwa Injil lain yang dimaksud adalah Taurat Yahudi. ${ }^{1}$ Sehingga orang-orang Kristen Yahudi memaksa orang-orang Kristen non-Yahudi untuk menaati Taurat agar mendapatkan pembenaran. Yahya melalui pendekatan historisnya, menyimpulkan bahwa orang-orang Kristen berlatar belakang Yahudi memaksa orang Kristen non-Yahudi untuk menaati hukum agar menjadi bagian dari umat Allah dan menikmati persekutuan di dalam Kristus. ${ }^{2}$ Dalam artikel ini menyimpulkan bahwa adanya satu kelompok orang Kristen yang sangat kuat memegang Taurat dan ditambah hukum-hukum Yahudi yang disebut Halakha. ${ }^{3}$ Kelompok tersebut mengutus memberitakan Injil yang lain, supaya jemaat-jemaat non Yahudi juga menaatinya.

\section{METODE PENELITIAN}

Jenis penelitian yang digunakan adalah kualitatif. Penelitian ini memberikan informasi berupa catatan dan data deskriptif yang berkaitan

'Jonathan Linebaugh, "The Grammar of the Gospel: Justification as a Theological Criterion in the Reformation and in Paul's Letter to the Galatians," Scottish Journal of Theology 71, no. 3 (August 14, 2018): 300-301, https://doi.org/10.1017/S0036930618000339.

2Pancha W. Yahya, "Sebuah Kritik Terhadap Pandangan James D. G. Dunn Tentang 'Melakukan Hukum Taurat' Dalam Galatia 2:16," Veritas: Jurnal Teologi Dan Pelayanan 14, no. 1 (April 1, 2013): 107-26, https://doi.org/10.36421/veritas.v14i1.270.

${ }^{3}$ Halakha adalah hukum-hukum Yahudi yang bukan hanya Pentateukh dan Perjanjian Lama.Agus Santoso mengutip pandangan Sanders bahwa Paulus sedang mengkritik satu kelompok atau mazhab dalam agama Yahudi yang menjunjung tinggi Halakha (selain Pentateukh dan Perjanjian lama) yang mereka sebut "Taurat". Selain Perjanjian Lama, maka Halakha juga harus dilakukan oleh orang yang ingin dibenarkan. Agus Santoso, Dia Menebus,Supaya Kita Diterima, Menjadi Anak: Tafsiran Surat Paulus Kepada Jemaat Di Galatia (Bandung: Bina Media Informasi, 2011), 11. 
dengan topik yang diteliti. ${ }^{4}$ Metode yang digunakan dalam penelitian ini adalah metode sinkronik, ${ }^{5}$ yakni historis-gramatikal. Metode historisgramatikal yaitu berusaha memahami teks-teks alkitabiah sebagaimana dimaksudkan penulis asli dan berangkat dari pandangan bahwa Alkitab adalah suatu karya tulis yang sudah final. ${ }^{6}$ Secara metodologis, penyelidikan historis-gramatikal mencakup beberapa aspek pengamatan, yaitu: penyelidikan kata (lexiology), penyelidikan tata bahasa dan relasi sintaksis, penyelidikan genre (gaya sastra), penyelidikan historis dilakukan untuk mengamati dua hal utama, yaitu: sejarah didalam teks dan sejarah dari teks. ${ }^{7}$

\section{HASIL DAN PEMBAHASA \\ KONTEKS AGAMA}

\section{Agama Yahudi (Yudaisme)}

Yudaisme adalah agama nasional dari bangsa Yahudi, tetapi pengikutnya tidak terbatas di kalangan Yahudi saja melainkan banyak pengikut yang berasal dari luar. ${ }^{8}$ Ciri-ciri Yudaisme adalah melakukan apa yang menjadi tuntutan hukum Taurat, adat istiadat dan moralitas merupakan bagian dari ibadah mereka. Orang-orang Yahudi mengakui bahwa Yahweh adalah satu-satunya Allah. Orang Yahudi juga berusaha semaksimal mungkin dalam menjalani kewajiban Taurat terutama dalam hal sunat, menaati hari Sabat dan tidak memakan makanan yang dianggap haram. ${ }^{9}$ Kegiatan-kegiatan tersebut tidak hanya untuk kepentingan diri sendiri, namun juga berdampak sosial. ${ }^{10}$ Namun hasilnya tidak ada yang sanggup memenuhi tuntutan hukum Taurat dengan sempurna, sehingga

"Yohanes Hasiholan Tampubolon, "Misi Gereja Di Era Kapitalisme Global: Eksplorasi Pelayanan Misi Yesus," Societas Dei: Jurnal Agama Dan Masyarakat 7, no. 2 (October 19, 2020): 197-217, https://doi.org/10.33550/sd.v7i2.137.

${ }^{5}$ Aeron Frior Sihombing, "Pendidikan Karakter Dalam Khotbah Di Bukit," Regula Fidei: Jurnal Pendidikan Agama Kristen 4, no. 1 (2019): 39.

'Yohanes Hasiholan Tampubolon et al., "Analisis Perbandingan GramatikalHistoris Bahasa Lidah Dalam 1 Korintus Dan Kisah Para Rasul," Jurnal Teologi Berita Hidup 3, no. 2 (March 25, 2021): 189-204, https://doi.org/10.38189/jtbh.v3i2.80.

${ }^{7}$ Haposan Silalahi, "Historical Grammatical: Sebuah Metode Hermeneutik Dalam Menemukan Makna Yang Tersembunyi Dalam Teks-Teks Alkitab,” Te Deum 8, no. 1 (2018): 17.

${ }^{8}$ Merrill C Tenney, Survei Perjanjian Baru (Malang: Gandum Mas, 2009), 101.

'Deky Hidnas Yan Nggadas, Tafsiran Alkitab: Injil Matius Pasal 1-22 (Jakarta: BPK Gunung Mulia, 2003), 58.

10Aeron Frior Sihombing, "Pemikiran Teologi Deuteronomis," TE DEUM Jurnal Teologi dan Pengembangan Pelayanan) 9, no. 1 (December 20, 2019): 1-32, https://doi.org/10.51828/td.v9i1.10. 
menjadikan mereka sebagai orang-orang yang munafik (Mrk. 2:23-3:36).11 Dengan berpegang pada hukum Taurat dengan segala rinciannya, seseorang menunjukkan ketaatan dan respons yang setia kepada Allah. Jemaat di Galatia mengalami pergumulan yang berasal dari agama Yudaisme tersebut. Orang-orang Yahudi mencoba meyakinkan mereka bahwa keselamatan didapat tidak cukup melalui iman kepada Yesus Kristus (Injil), sehingga persoalan ini menjadi salah satu keresahan yang melatarbelakangi Paulus menuliskan suratnya.

Drane dan Sihombing berpendapat bahwa berpegang pada hukum dan peraturan-peraturan merupakan hal utama dalam agama Yahudi, agar menjadi orang baik, seseorang harus memelihara hukum Taurat di tengah konteks saat itu. ${ }^{1213}$ Taurat juga menjadi tolak ukur dalam hubungan dengan Allah dan sesama. ${ }^{14}$ Packer juga berpandangan yang sama, menurutnya tanpa hukum Taurat, orang-orang Yahudi tidak akan mempunyai harapan, sehingga mereka tidak boleh kompromi dalam segi kepercayaan karena akan membawa mereka jauh dari firman Tuhan dan akhirnya tenggelam dalam budaya yang ada di sekeliling mereka. ${ }^{15}$ Namun, agama Yudaisme justru tidak lagi berpegang pada Taurat, mereka terjebak pada hukum-hukum tertulis yang berasal dari tafsiran terhadap Taurat.

\section{Agama Kristen Yahudi}

Komunitas Kristen pertama dimulai dari orang-orang percaya pada saat hari Pentakosta di Yerusalem. Menurut Lukas, orang-orang yang dibaptis pada hari itu berjumlah tiga ribu orang (Kis. 2:37-41) dan hampir seluruhnya adalah orang Yahudi. Mereka berasal dari berbagai daerah: Partia, Media, Elam dan Mesopotamia di bagian Timur. Ada juga yang berasal dari Kapadokia, Pontus, Asia, Phygia dan Pamphilia di bagian Utara; dari Arab, Mesir, Libya dan Cyrene di sepanjang pantai utara Afrika dan Arab di bagian selatan dan Roma. Para peziarah yang dibaptis ini adalah orang-orang yang taat kepada hukum Taurat dan memiliki minat

11Packer J.I, Dunia Perjanjian Baru (Malang: Gandum Mas, 1995), 177.

12John Drane, Memahami Perjanjian Baru (Jakarta: BPK Gunung Mulia, 2005), 252.

${ }^{13}$ Aeron Frior Sihombing, "Relasi Etika Perjanjian Lama Dengan Etika Global Hans Kung," TE DEUM (Jurnal Teologi dan Pengembangan Pelayanan) 4, no. 2 (April 12, 2021): 163 92, https://doi.org/10.51828/td.v4i2.61.

${ }^{14}$ Sunarto, "Integritas Seorang Pengkhotbah dan Kualitas Khotbah Dalam Pemberitaan Firman Tuhan," TE DEUM (Jurnal Teologi dan Pengembangan Pelayanan) 7, no. 1 (April 27, 2021): 77-99, https://doi.org/10.51828/td.v7i1.103.

15J.I, Dunia Perjanjian Baru, 94. 
untuk beribadah di Yerusalem. ${ }^{16}$ Tentu saja mereka semua menaruh perhatian terhadap agama Yahudi, kalau tidak, mereka tidak akan melakukan perjalanan ke Yerusalem guna menghadiri perayaan keagamaan. Oleh karena itu, pada awalnya, orang-orang yang dibaptis ini tetap melakukan ibadah di Bait Allah dan mengikuti ritual-ritual keagamaan Yahudi. ${ }^{17}$ Namun, ada juga dari antara mereka mungkin saja bukan orang Yahudi tetapi orang yang menganut agama Yahudi. Drane menjelaskan bahwa tidak semua non-Yahudi yang datang ke Yerusalem, mereka sudah menjadi penganut agama Yahudi dan menerima seluruh hukum Yahudi, karena keturunan Yahudi-pun di berbagai tempat dari kekaisaran Roma, mempunyai latar belakang dan pandangan agak berlainan dengan orang Yahudi yang dilahirkan dan dibesarkan di Palestina sendiri. ${ }^{18}$

Umat Kristen mula-mula dikenal sebagai "Sekte orang Nasrani" (Kis. 24:5, 14) yang dianggap sebagai suatu cabang dari kepercayaan induk Yudaisme. ${ }^{19}$ Di Kota Antiokhialah murid-murid untuk pertama kalinya disebut Kristen (Kis. 11:26b). Hakh menyatakan bahwa di kota Antiokhia inilah para pengikut Yesus untuk pertama kalinya disebut "orang Kristen", namun orang Yahudi tidak pernah menyebut nama ini karena memiliki hubungan dengan Kristus (Yun. Christos; Ibr. Masiab). ${ }^{20}$ Hal ini dapat dilihat bahwa Yesus sendiri adalah seorang yang lahir dalam sebuah keluarga Yahudi (Mat. 1:16) dan disunat sama seperti anak Yahudi lainnya (Mat. 2:21), sebagai seorang anak, Ia dibawah ke Yerusalem untuk mengikuti perayaan paskah (Mat. 2:41) dan sepanjang hidup-Nya, Ia menjalankan adat kebiasaan bangsa Yahudi serta hidup ditengah-tengah masyarakat-Nya. Murid-murid Yesus juga berasal dari agama Yahudi, sehingga mereka pun mendukung dan memelihara dengan setia upacara-upacara ibadah Yahudi di Sinagoge. Mereka juga memelihara pesta-pesta agama Yahudi yang besar dan kadang-kadang mereka berkhotbah di pelataran Bait Allah (Kis. 3:116). Namun, akhirnya menjadi masalah ketika Petrus dan Yohanes ditangkap dan dilarang mengajarkan tentang nama Yesus (Kis. 4:18).

16Samuel Benyamin Hakh, Perjanjian Baru: Sejarah Pengantar dan Pokok-Pokok Teologisnya (Bandung: Bina Media Informasi, 2010), 78.

${ }^{17}$ Hakh, 78.

18Drane, Memahami Perjanjian Baru, 34.

${ }^{19}$ Tenney, Survei Perjanjian Baru, 102.

${ }^{20}$ Hakh, Perjanjian Baru: Sejarah Pengantar dan Pokok-Pokok Teologisnya. 


\section{Agama Kristen Non-Yahudi}

Bukti internal menunjukkan bahwa kemungkinan penerima surat Galatia adalah bukanlah orang Yahudi asli atau orang yang pernah memeluk agama Yudaisme, hal ini dibuktikan dengan kecenderungan Paulus cenderung mengutip teks dalam Perjanjian Lama dengan menggunakan teks septuaginta. ${ }^{21} \mathrm{Hal}$ ini sejalan dengan visi Paulus dan ia telah beberapa kali mengatakan dalam suratnya, bahwa ia telah dipanggil khusus oleh Allah untuk memberitakan Injil kepada bangsa bukan Yahudi (Rm. 11:13; Rm. 15:16).22

Dorongan utama misi kepada orang bukan Yahudi bagaimanapun muncul dari perjalanan rasul Paulus. Sebagai hasil dari perjalananperjalanan misinya ke Asia Kecil dan Yunani, agama Kristen berkembang di wilayah Laut Tengah. Siprus dan beberapa bagian Asia Kecil adalah tempat tujuan perjalanan pertamanya; Makedonia yang kedua dan yang ketiga lebih meluas di Asia Kecil. ${ }^{23}$ Hakh mengatakan:

"Pernyataan Yesus tentang diri-Nya, sebagai penggenapan kepercayaan Perjanjian Lama memberi pengikut-pengikutnya suatu keuntungan. Orang-orang Yunani dan Romawi dan orangorang Yahudi dalam perantauan dengan sendirinya ingin mendengar apa yang hendak dikatakan oleh orang-orang Kristen. Karena Perjanjian Lama telah diterjemahkan dalam bahasa Yunani, para pemberita Injil pertama tidak menemui kesulitan untuk menerangkan berita mereka secara rinci. Di samping itu agama Kristen mempunyai daya tarik tersendiri karena merupakan salah satu agama yang masuk dari timur. Palestina dianggap sebagai terletak di batas timur dunia yang beradab dan apa saja yang berasal dari wilayah itu setidak-tidaknya akan didengar oleh mereka yang kecewa dengan warisan agama mereka sendiri." 24

Strategi misi yang dilakukan Paulus terlebih dahulu mendatangi Sinagoge-Sinagoge dan misinya sudah tentu untuk orang bukan Yahudi dan gereja yang sudah berdiri yang terdiri atas orang yahudi dan bukan Yahudi.

21Philip Suciadi Chia, Memahami Kitab-Kitab Perjanjian Lama Di Dalam Perjanjian Baru (Yogyakarta: Stiletto Indie Book, n.d.), 253.

22Yohanes Hasiholan Tampubolon, "Kontekstualisasi Metodologi Misiologi Paulus Dalam Dunia Kontemporer," Excelsis Deo: Jurnal Teologi, Misiologi, Dan Pendidikan 3, no. 2 (December 31, 2019): 13-25, https://doi.org/10.51730/ed.v3i2.13.

${ }^{23}$ Gordon J McConville, Sejarah Alkitab," in Tafsiran Alkitab Abad Ke 21: 3 MatiusWabyu, ed. D.A Carson (Jakarta: Yayasan Komunikasi Bina Kasih, 2017).

${ }^{24}$ Hakh, Perjanjian Baru: Sejarah Pengantar Dan Pokok-Pokok. Teologisnya, 31. 
Namun, pertanyaan mengenai upacara hukum Taurat selalu menjadi isu karena seringnya mendatangi Sinagoge, tetapi juga dalam gereja ada orang yang bersemangat untuk mengajarkan suatu pemahaman Yahudi tentang Injil. ${ }^{25}$ Paulus melawan mereka secara berapi-api dalam suratnya kepada jemaat Galatia (Gal. 3:1-5; 5:2-12). Benar bahwa Paulus juga pernah menyuruh Timotius muridnya untuk disunatkan sesuai dengan tujuan misinya kepada orang Yahudi (Kis. 16:3), meskipun dia tahu bahwa sunat sendiri bukan yang terutama (1Kor. 7:19). Sebab hakikat Injil yaitu penyelamatan Allah oleh anugerah melalui Kristus dan bukan karena hukum. ${ }^{26}$

\section{Hubungan ANTARA YUdAISME, KRISTEN YAHUdI DAN NON-YAHUDI}

Pada awalnya, pemisahan antara Kristen dan Yudaisme tidak berlangsung secara cepat. Gordon menjelaskan bahwa perlawanan terhadap orang Kristen muncul dari kaum Saduki yang menolak ajaran tentang kebangkitan dan tentu implikasinya bagi Mesianik (Kis. 4-1-3; 5:17-18). Puncaknya adalah ketika Stefanus dengan terang-terangan menentang Baik Suci dan Hukum Taurat, sehingga membuat para pemimpin Yahudi bersatu dan menyerahkan dia untuk di hukum mati (Kis. 7:42-60). Lebih lanjut, Gordon mengatakan bahwa:

"Rupanya sejak awal orang Kristen sudah dianggap sebagai kelompok tersendiri oleh para pemimpin Yahudi. Penganiayaan selanjutnya oleh Herodes Agripa I (raja Yudea, 41-44 M) mengkhususkan orang Kristen sehingga menyenangkan 'orang Yahudi' (Kis. 12:1-3). Hubungan memburuk ketika orang Kristen tidak bergabung dalam perang Yahudi pada tahun 66-73 M. Orang Kristen menjadi sasaran untuk balas dendam dan gereja Yerusalem melarikan diri ke Pella di wilayah seberang sungai Yordan. Namun, putusnya hubungan gereja dengan Sinagoge secara tegas mungkin tidak terjadi sebelum pemberontakan Bar-Kokhba pada tahun 132-135 M."27

Dengan adanya masa-masa ini, status hukum Taurat dan identitas keyahudian orang Kristen merupakan suatu masalah yang menyakitkan buat mereka. Hal ini sangat jelas terlihat saat sebagian dari anggota gereja di

\footnotetext{
${ }^{25}$ McConville, Sejarah Alkitab," in Tafsiran Alkitab Abad Ke 21: 3 Matius-Wabyu, 31.

${ }^{26} \mathrm{McC}$ Conville, 32.

${ }^{27}$ McConville, 32.
} 
Yerusalem tidak mau melepaskan berbagai tradisi Yahudi yang sudah mendarah daging, seperti terlihat pada kehadiran orang Farisi yang sudah percaya dalam kumpulan dalam sidang mereka di Yerusalem (Kis. 15:5). Saat itu mereka dikalahkan oleh Petrus, namun pengaruh mereka tetap cukup kuat. Ketika Paulus kembali ke Yerusalem dari perjalanan misinya yang ketiga, Yakobus saudara lelaki Yesus yang pada saat itu rupanya menjadi pemimpin di Yerusalem, mengungkapkan kegelisahan sejumlah anggotanya bahwa mungkin Paulus membujuk orang yang baru percaya agar tidak lagi menjalankan peribadatan menurut hukum Taurat (Kis. 21:20-26). ${ }^{28}$ Mengenai hal ini, dapat dilihat bagaimana tindakan orang Yahudi yang berasal dari Asia, sangat membenci Paulus dan menginginkan agar ditangkap dan dipenjarakan (Kis. 21:27-28).

Lama setelah tiba di Antiokhia (perjalanan misi pertama Paulus), orang-orang Kristen Yahudi dari Yerusalem, yang masih tunduk kepada hukum Taurat dan tardisi-tradisinya, juga tiba di Antiokhia. Mereka menuntut agar orang Kristen non-Yahudi harus masuk ke dalam agama Yahudi dengan jalan sunat sehingga mereka memperoleh keselamatan (Kis. 15:1). Rasul Paulus menolak alasan itu dengan mengatakan bahwa orang non-Yahudi yang hendak masuk Kristen tidak perlu sunat, karena sunat itu adalah suatu tindakan keagamaan yang bersifat lahiriah. Bahkan menurut Paulus, Perjanjian Lama mengatakan bahwa Abraham dibenarkan oleh imannya jauh sebelum hukum Musa diberikan. ${ }^{29}$ Oleh karena masalah ini, maka jemaat di Antiokhia menunjuk Paulus, Barnabas dan beberapa orang Kristen lainnya untuk pergi ke Yerusalem agar bertemu para rasul dalam rangka memecahkan masalah itu (Kis. 1-29; Gal. 2:1-10). Dalam sidang itu, Petrus berdiri di pihak utusan dari jemaat Antiokhia dan mengingatkan bahwa ketika ia memberitakan Injil di rumah Kornelius, seorang perwira pasukan Romawi, Roh Kudus turun ke atas semua orang dalam rumah itu yang semuanya adalah orang bukan Yahudi. Lalu mereka dibaptis tanpa melakukan ritual penyunatan (Kis. 10:44-48). Yakobus saudara Yesus, juga memberikan pendapat bahwa nabi-nabi Perjanjian Lama juga telah menubuatkan tentang masuknya orang-orang bukan Yahudi ini (Yes. 45:21; Yer. 12:15; Am. 9:11-12).

Sidang itu kemudian menyusun sebuah surat yang isinya mengakui bahwa orang Kristen non-Yahudi adalah "saudara" dan menolak tuntutan orang Kristen Yahudi di Yerusalem. Sidang itu menegaskan bahwa

${ }^{28} \mathrm{McC}$ Conville, 33.

${ }^{29}$ Hakh, Perjanjian Baru: Sejarah Pengantar Dan Pokok-Pokok Teologisnya, 90. 
masuknya orang bukan Yahudi menjadi Kristen adalah karena pekerjaan Roh Kudus, sehingga tidak perlu diletakkan beban di atas pundak mereka dengan melakukan ritual sunat. Akan tetapi, ada beberapa larangan yang harus mereka patuhi untuk memelihara hubungan yang harmonis antar kedua gereja. Larangan itu berkaitan dengan praktik kekafiran yang menjijikan orang Yahudi. Larangan itu adalah orang Kristen non-Yahudi dilarang: Pertama, makan makanan yang telah dipersembahkan kepada berhala. Kedua, makan darah dan daging binatang, yang darahnya tidak dikeluarkan waktu disembelih. Ketiga, melakukan percabulan (Kis. 15:29). Sidang itu sangatlah bijaksana dalam mengatasi persoalan yang sedang dihadapi oleh Kristen non-Yahudi. ${ }^{30}$

Gunawan juga melihat masalah yang sama, sehingga dia melakukan penelitian tentang adanya pertentangan antara agama Yahudi dengan nonYahudi khususnya di Galatia. Ia mengatakan bahwa tuntutan sunat dalam jemaat di Galatia adalah isu yang nampak dari permukaan, namun sebenarnya ada permasalahan yang utama yaitu ketidakmauan kelompok Kristen Yahudi untuk menerima kelompok Kristen non-Yahudi dalam komunitas umat Allah, karena untuk masuk dalam komunitas umat Allah maka harus di sunat. ${ }^{31}$

Jadi, perihal hubungan antara Yudaisme, Kristen Yahudi dan Kristen non-Yahudi dari pembahasan di atas, penulis menggambarkan suatu hubungan yang tidak baik khususnya saat-saat kekristenan awal. Yudaisme membenci orang Kristen Yahudi karena memiliki ajaran yang berbeda dengan mereka khususnya tentang Kristus. Sedangkan, Kristen Yahudi tidak bisa menerima Kristen non-Yahudi dengan alasan bahwa orang Kristen non-Yahudi harus di sunatkan terlebih dahulu untuk masuk dalam komunitas umat Allah. Karena didasarkan pada pandangan bahwa hanya orang Yahudi Kristen yang bisa disebut sebagai umat Allah.

${ }^{30}$ Hakh, 91.

${ }^{31}$ Chandra Gunawan, "Ketegangan Hubungan Yahudi Dan Bukan Yahudi Dalam Yudaisme Bait Allah Kedua Dan Dalam Surat Galatia," Veritas, Jurnal Teologi Dan Pelayanan, 2011, 84, http://repository.seabs.ac.id/handle/123456789/226. 


\section{Struktur Teks Galatia 1:6-732}

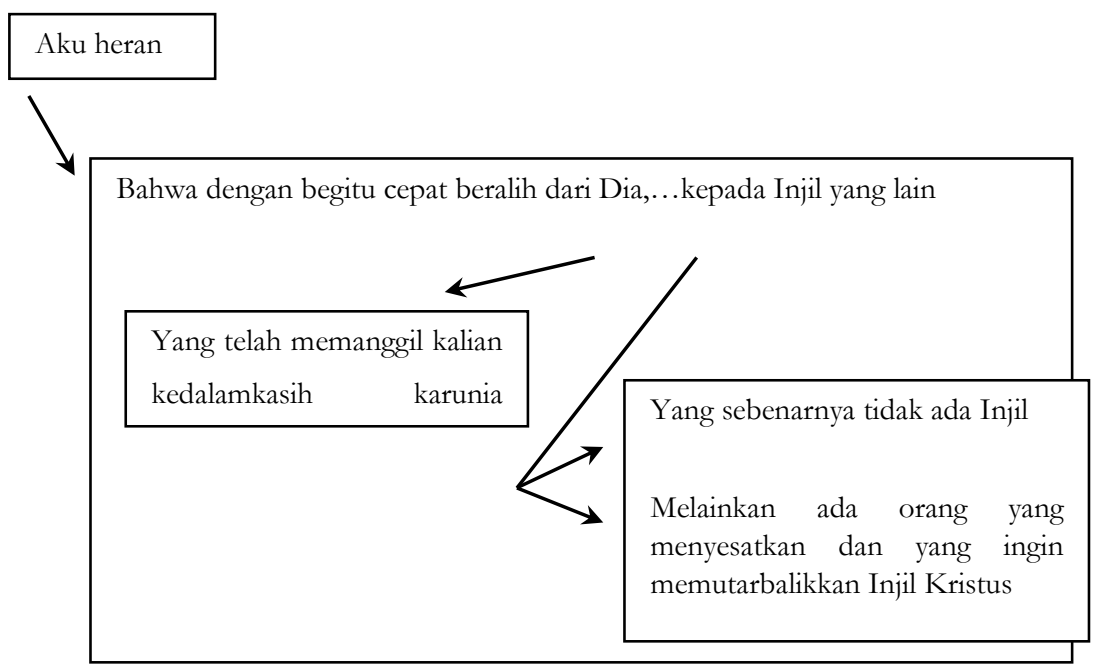

Dari struktur diatas mengenai kitab Galatia 1:6-7, dapat dilihat bahwa alasan mengapa Paulus mengatakan "aku heran" terlihat dalam struktur bahwa orang Galatia sedang beralih dari Allah yang telah memanggil mereka melalui kasih karunia Kristus, kepada Injil yang lain. Sehingga Paulus menjelaskan bahwa tidak ada Injil lain, hanya ada orang yang menyesatkan dan memutarbalikkan Injil Kristus. Jadi, yang dimaksud dengan "Injil lain" adalah tindakan menyesatkan dan memutarbalikkan Injil Kristus.

\section{TAFSIRAN GALATIA 1:6}

\section{Aku Heran (thaumazo)}

Tramper \& David berpendapat bahwa Paulus mengungkapkan emosi yang sangat kuat memikirkan perpindahan iman orang Galatia dari Injil Kristus, untuk memeluk Injil yang berbeda. ${ }^{33}$ Ungkapan keheranan sebenarnya adalah bentuk teguran karena begitu cepat berpaling dari kasih karunia Kristus, yang telah memberikan nyawa-Nya untuk dosa mereka,

32Santoso, Dia Menebus,Supaya Kita Diterima, Menjadi Anak: Tafsiran Surat Paulus Kepada Jemaat Di Galatia, 45.

${ }^{33}$ Tremper Longman and David E. Garland, The Expositor's Bible Commentary: RomanGalatians (Grand Rapids: Zondervan, 2005), 565. 
sesuai dengan kehendak Allah. ${ }^{34}$ Hendriksen mengatakan Paulus heran karena orang Galatia sedang mengubah posisi mereka dan mentransfer kesetiaan dari Allah yang telah memanggil mereka, melalui Roh Kudus dalam hati setiap individu yaitu undangan keselamatan, penuh dan gratis melalui jalan pengudusan, kepada sesuatu yang lain dengan begitu cepatnya setelah pertobatan mereka (Gal. 4:12-15; 5:7).35 "aku heran" adalah frasa yang dipakai oleh Paulus untuk menyatakan kejengkelan terhadap jemaat di Galatia, namun bersifat pastoral. ${ }^{36}$ Keheranan Paulus karena waktu mendirikan jemaat Galatia, Paulus telah menanamkan Injil yang "benar". Tetapi tidak lama setelah Paulus meninggalkan Galatia, Paulus mendapat berita, bahwa ada beberapa orang yang mengikuti ajaran kelompok Yakobus yang disebutnya saudara-saudara palsu dimana mereka menyunatkan diri (Gal. 5:11) dan mengikuti ajaran "Taurat". 37

Jadi, ada dua poin penting mengapa Paulus mengatakan "aku heran", pertama berkaitan dengan waktu yaitu jarak pertobatan dan peralihan mereka kepada ajaran lain terlalu cepat dan yang kedua adalah orang Kristen Galatia yang sedang dan begitu cepat meninggalkan imannya, yaitu meninggalkan Allah yang telah memanggil mereka kepada keselamatan, sehingga Paulus merasa kecewa atau emosi atas hal tersebut.

\section{Lekas Berbalik Dari Pada Dia}

Kata "lekas" (tacheos) merujuk pada waktu yang cepat atau singkat. Namun, dalam teks Galatia 1:6, kata ini dipakai untuk menunjukkan bahwa mereka sangat mudah terpengaruh dan berbalik dari Allah. Susanto berpendapat mengenai proses peralihan iman yang berlangsung begitu cepat: seperti yang telah dikatakan diatas, bahwa tidak berapa lama setelah Paulus meninggalkan Galatia, maka ada beberapa dari anggota jemaat yang mengikuti ajaran yang menyesatkan ini. ${ }^{38}$ Kata "berbalik" (metatithemi) adalah kata yang menggambarkan perubahan sikap jemaat Galatia yang sedang berlangsung saat itu, yakni meninggalkan Allah, atau meninggalkan iman mereka kepada Allah. Kenneth dan John melihat bahwa kegelisahan

${ }^{34}$ Longman and Garland, 565.

35William Hendriksen, New Testament Commentary: Galatians, Ephesians, Philippians, Colossians, and Philemon (Grand Rapids: Inter Varsity Press, 2007), 38.

${ }^{36}$ Santoso, Dia Menebus,Supaya Kita Diterima, Menjadi Anak: Tafsiran Surat Paulus Kepada Jemaat Di Galatia, 46.

37Taurat disini adalah Halakha yang dianut oleh suatu kelompok atau mazhab dalam agama Yahudi dan mereka percaya bahwa selain Perjanjian Lama, maka Halakha juga harus dilakukan oleh orang yang ingin dibenarkan. Santoso, 11.

${ }^{38}$ Santoso, 47. 
Paulus kepada jemaat di Galatia terlihat dari kata-kata yang dituliskan, menunjukkan juga alasan mengapa Paulus tergerak menulis surat, karena "meninggalkan" Allah yang telah memanggil mereka untuk beriman kepada Yesus Kristus. ${ }^{39}$ Kata Yunani yang digunakan dalam Galatia 1:6, merujuk pada perubahan sikap. Perubahan itu bukanlah hasil pengaruh luar, tetapi atas kebebasan mereka sendiri. Ada harapan bagi jemaat Galatia bahwa mereka masih dalam proses meninggalkan dan mungkin dapat diperbaiki. ${ }^{40}$ Jika mereka meninggalkan Injil yang diberitakan Paulus, maka sekaligus mereka juga meninggalkan Allah yang telah menganugerahkan kasih karunia-Nya melalui Yesus Kristus. ${ }^{41}$ Silva mengatakan bahwa tindakan mereka bersifat pribadi, pada kenyataannya mereka sedang meninggalkan Yesus yang dengan penuh kasih memanggil mereka kepada diri-Nya. ${ }^{42}$

\section{Kasih Karunia Kristus}

Kata "memanggil" (kaleo), adalah kata yang dipakai untuk menyatakan panggilan Allah atau undangan Allah berkaitan dengan keselamatan dan menjadi milik Allah (Bdk. Gal. 5:1; Rm. 8:30; 9:11; 1Kor. 1:9). Penggunaan kata ini juga dipakai oleh para penulis kitab Injil, bagaimana Yesus memanggil murid-murid-Nya, untuk melayani. "Kasih karunia Kristus" (charis Christos) atau "rahmat Kristus" adalah cara Allah memanggil orang Galatia untuk memperoleh keselamatan dan menjadi milik Allah, bukan dengan cara melakukan hukum Taurat. Paulus menegaskan bahwa hakikat Injil yang sebenarnya adalah Allah sendiri yang memanggil dan itu merupakan kasih karunia, bukan jasa atau perbuatan manusia. ${ }^{43}$ Bruce, mengatakan bahwa rahmat yang dibicarakan oleh Paulus bukan hanya sikap kebajikan dari Allah atau Kristus, tetapi ditunjukkan dalam tindakan penyelamatan Allah melalui kematian Kristus, di mana mereka yang tidak layak dan tidak benar (Rm. 5:6), ditebus, dibenarkan dan didamaikan. ${ }^{44}$ Jadi kasih karunia dan hukum saling terpisah sebagai cara pembenaran (Gal. 5:4 dan Rm. 11:6).

${ }^{39}$ Kenneth L Barker and John R. Kohlenbergerr III, The Expositor's Bible Commentary: Abridged Edition New Testament (Grand Rapids: Zondervan, 1994), 709.

${ }^{40}$ Barker and III, The Expositor's Bible Commentary: Abridged Edition New Testament.

${ }^{41}$ Santoso, Dia Menebus,Supaya Kita Diterima, Menjadi Anak: Tafsiran Surat Paulus Kepada Jemaat Di Galatia, 47.

42D. A Carson, Tafsiran Alkitab Abad Ke-21, 3, Matius-Wabyu (Jakarta: Yayasan Komunikasi Bina Kasih, 2017), 441.

${ }^{43}$ Barker and III, The Expositor's Bible Commentary: Abridged Edition New Testament, 708.

${ }^{44}$ F.F. Bruce, The Epistle to the Galatians: The New International Greek Testament Commentary (Grand Rapids: Eerdmans, 2013), 80. 
Jadi, kasih karunia Kristus dalam teks Galatia 1:6 adalah rahmat atau anugerah Allah, inisiatif Allah sendiri dalam Yesus Kristus yang memberikan keselamatan bagi orang berdosa yang harusnya tidak layak menerima keselamatan itu sendiri dan menikmati hubungan dengan Allah. Cara Allah menyelamatkan orang berdosa melalui kematian Kristus sehingga orang berdosa memperolehnya melalui iman dan bukan dengan perbuatan atau usaha manusia. Pemberian Allah secara cuma-cuma, Allah sendiri yang bertindak memberikannya.

\section{Kepada Injil Lain yang Sebenarnya Bukan Injil}

Kata "Injil" (enangelion) dapat diartikan sebagai berita baik atau kabar baik. Dalam Perjanjian Baru, kata ini hanya dipakai untuk kabar baik yang dari Allah. Alkitab memakai kata "Injil" yaitu berita gembira dari Allah tentang Yesus Kristus (Mrk. 1:1). Seperti dalam kitab Injil sinoptik yang menuliskan kabar baik tentang Kristus yang dimulai dari kelahiran-Nya, kematian-Nya, kebangkitan dan kembali ke surga. Kabar baik itu adalah Allah sendiri yang berinkarnasi dalam diri Yesus Kristus yang hidup tanpa dosa, mati sebagai ganti orang berdosa dan bangkit kembali dan dengan demikian menyelamatkan semua orang berdosa yang percaya kepada-Nya. ${ }^{45}$ Paulus sendiri memberi definisi tentang Injil yaitu sebagai kekuatan Allah yang menyelamatkan setiap orang yang percaya (Rm. 1:16; Ef. 1:13). Dalam Galatia 1:6, Paulus menyebut sebagai "heteros enanggelion" atau Injil yang lain atau yang berbeda dari Injil kasih karunia. Dan bahkan Galatia 1:7a Paulus meluruskan lagi dengan mengatakan "sebenarnya bukan Injil" dengan alasan bahwa tidak ada Injil yang lain selain Injil tentang kasih karunia Kristus. Jadi orang Galatia sedang meninggalkan Injil tentang kasih karunia Allah dalam Yesus Kristus, kepada sesuatu ajaran keselamatan yang berbeda atau yang lain.

Bruce mengatakan bahwa pemakaian kata "heteros" (berbeda jenis) dan "allos" (yang lain, dari jenis yang sama), memiliki makna yang kuat. Paulus memakai kata "heteros" dalam Galatia 1:6 untuk menjelaskan bahwa apa yang diajarkan orang lain kepada jemaat Galatia itu adalah sesuatu yang berbeda dengan ajaran Paulus. Sedangkan pemakaian kata "allos" dalam Galatia 1:7 adalah untuk menjelaskan bahwa pada kenyataannya itu bukan Injil dan tidak ada Injil lain selain yang diberitakan oleh Paulus. ${ }^{46}$ Dalam arti

${ }^{45}$ Pater S. Wong, Injil Yesus Kristus: Sebuah Pengantar Teologi Injili (Jakarta: Yayasan Kartidaya, 2011), 45.

${ }^{46}$ F.F. Bruce, The Epistle to the Galatians: The New International Greek Testament Commentary, 81. 
yang tepat dari kata Injil adalah proklamasi pembenaran oleh iman dan bukan dari perbuatan. Bruce melihat bahwa Paulus menyebutnya bukan Injil karena pesannya adalah pesan perbudakan, bukan kebebasan. Suatu bentuk doktrin keselamatan dari Paulus yang sebelumnya menegakkan pembenaran melalui hukum, sekarang telah dibebaskan melalui Injil yang diperoleh dari Yesus Kristus di jalan Damaskus (Gal. 1:12) dan Injil inilah yang diberitakan kepada orang Galatia. ${ }^{47}$

Paulus menggunakan dua bahasa yang kontradiktif: Injil Kristus dan Injil yang lain. Yang dimaksud dengan Injil Kristus adalah pembenaran oleh karena iman kepada Kristus dan inilah yang dijaga oleh Paulus. Sedangkan Injil yang lain adalah pembenaran dengan cara harus menjadi umat Israel dengan menjadi proselit dan mengikuti adat istiadatnya seperti sunat dan lainnya. ${ }^{48}$ William mengatakan bahwa Paulus menyebut Injil yang berbeda karena menyatakan iman yang ditambahkan hukum sebagai jalan keselamatan dan ini adalah penyimpangan dari Injil yang benar. ${ }^{49}$ Paulus menyebut Injil yang lain "beteros" dalam pengertian bahwa para penghasut mencoba menyampaikan pesan mereka sebagai suatu kesatuan. Namun berbeda dengan Injil sejati yang telah diberitakan, karena Paulus sekarang menyangkal bahwa Injil palsu itu memiliki klaim apapun sebagai Injil (Gal. 1:7a). Paulus menjelaskan bahwa Injil yang menarik orang Galatia sebenarnya bukanlah "Injil yang lain", melainkan cara untuk mentransfer kesetiaan mereka dari Injil yang benar, namun para musuhnya mengklaim sebagai Injil. ${ }^{50}$ Jadi Injil lain itu adalah ajaran yang sesat bahwa orang dapat berbalik dan memiliki hubungan kembali dengan Allah dengan cara melakukan peraturan-peraturan hukum Taurat, termasuk memberi diri di sunat. Orang-orang yang menyebarkan Injil lain ini telah menyesatkan orang-orang Kristen Galatia dengan mengatakan Injil ini adalah kabar baik, padahal bukan. ${ }^{51}$

\footnotetext{
${ }^{47}$ F.F. Bruce, 81.

${ }^{48}$ F.F. Bruce, 47.

${ }^{49}$ Hendriksen, New Testament Commentary: Galatians, Ephesians, Philippians, Colossians, and Philemon, 39.

${ }^{50}$ Douglas. J. Moo, Galatians (Grand Rapids: Backer, 2013), 78.

${ }^{51}$ Helen Miehle L., Pedoman Penafsiran Alkitab: Surat Paulus Kepada Jemaat Di Galatia (Jakarta: LAI, 2011), 14.
} 


\section{TAFSIRAN GALATIA $1: 7$}

\section{Menyesatkan dan Memutarbalikkan Injil Kristus}

Kata "menyesatkan" (tarasso), juga dapat diartikan sebagai "mengacaukan" atau "menggelisahkan", terjemahan KJV memakai kata trouble dan terjemahan NIV, memakai kata confusion artinya "kebingungan/membingungkan". Beberapa terjemahan ini menggambarkan keadaan yang sedang terjadi di jemaat Galatia, dimana mereka sedang menghadapi masalah atau sesuatu yang menggelisahkan iman mereka. Masalah tersebut adalah tindakan penyesatan yang mengacaukan iman mereka, pemahaman mereka tentang keselamatan sedang dikacaukan sehingga membuat suatu kegelisahan yang menggoncangkan iman jemaat. Iman dan pemahaman mereka akan keselamatan yang mereka terima dari Paulus mengenai Injil Kristus sedang "diputarbalikkan" inilah yang menjadi inti permasalahan, yang menggelisahkan dan menyesatkan jemaat. Kata "memutarbalikkan" (metastrepho) diartikan sebagai "menyesatkan, membelokkan, mengubah dan memutarbalikkan". Kata ini menggambarkan bagaimana usaha pengajar sesat yang masuk di jemaat Galatia untuk mengubah atau membelokkan iman jemaat khususnya dalam hal keselamatan harus ditambahkan dengan perbuatan manusia untuk memperolehnya.

Longman dan Garland, mereka melihat bahwa jemaat Galatia sedang dikepung oleh orang-orang yang memberitakan Injil lain. Mereka adalah lawan Paulus yang biasanya diidentifikasikan sebagai Yudaisme, yang memaksa para petobat Galatia untuk mengikuti gaya hidup Yahudi yang berorientasi pada hukum. Lawan atau musuh Paulus sengaja memutarbalikkan Injil Kristus sehingga membuat jemaat Galatia bingung karena Injil yang diberitakan bukan mengarah kepada kasih karunia dan penebusan Allah di dalam Yesus Kristus. Inilah yang menyesatkan kebenaran dan penyimpangan dari kebenaran Injil. ${ }^{52}$ Douglas mengatakan bahwa pemakaian kata kerja "mengganggu/menggelisahkan" menunjuk kepada orang Kristen Yahudi yang bersikeras bahwa orang bukan Yahudi harus disunat dan mematuhi hukum Musa (Kis. 15:24). Mereka membuat jemaat Galatia bingung dengan mencoba untuk menyesatkan atau mengubah Injil Kristus dan hal itu sedang berlangsung tetapi mereka belum berhasil. 53

52Longman and Garland, The Expositor's Bible Commentary: Roman-Galatians, 565.

${ }^{53}$ Moo, Galatians, 78. 
Bruce mengatakan bahwa memutarbalikkan Injil Kristus, yaitu dengan menyampaikan bahwa perlunya sunat bagi laki-laki yang sudah bertobat di jemaat Galatia, karena sunat adalah syarat yang sangat diperlukan untuk pembenaran dihadapan Tuhan. Namun, dalam teks tidak terlihat identitas pembuat masalah di Galatia, karena Paulus hanya merujuk kepada orang ketiga dan kepada jemaat Galatia sebagai orang kedua. Jadi, desakan dari orang ketiga adalah melakukan sunat (Gal. 5:6; 6:15), adalah merupakan kemunduran dari pembenaran oleh kasih karunia menjadi pembenaran oleh perbuatan dan kemunduran dari kebebasan Roh menjadi perbudakan agama, hal inilah yang merusak Injil yang otentik karena mengganti dasar yang salah yang telah ditetapkan oleh Tuhan. ${ }^{54}$ Jadi, para pengikut Yudaisme telah memutarbalikkan Injil dan telah mengarahkannya kepada Taurat, bagi mereka hukum Taurat dan Injil berjalan bersamaan (Kis. 15:1). ${ }^{55}$ Tetapi Paulus dengan tegas mengatakan bahwa Injil Kristus (kasih karunia Allah), tidak bisa dicampur dengan hukum Taurat (Gal $2: 21) .56$

Barclay menjelaskan bahwa banyak orang Yahudi yang telah menerima Kristus, tetapi mereka percaya bahwa janji-janji dan segala anugerah-Nya hanya untuk kaum Yahudi saja dan tidak ada seorang kafir pun yang dapat dibenarkan dan menerima hak istimewa itu. ${ }^{57}$ Oleh sebab itu, mereka percaya bahwa kekristenan adalah anugerah Allah dan hanya orang Yahudi saja yang patut menikmatinya. Jadi, jalan keluar bagi orang kafir adalah jika ingin menjadi Kristen yaitu dengan cara di Yahudikan, melakukan sunat dan mematuhi seluruh hukum Taurat. ${ }^{58}$ Barclay juga melihat bahwa orang Kristen Yahudi mengajarkan keselamatan diperoleh dengan cara mendapatkan belas kasihan Allah, termasuk melakukan sunat dan mempersembahkan seluruh hidupnya melakukan segala tata tertib dan aturan-aturan hukum. Jadi, setiap perbuatan baik yang mereka lakukan adalah tabungan untuk masuk ke dalam Kerajaan Allah dan bagi Paulus ini adalah kemustahilan yang mutlak dan memutarbalikkan kebenaran. ${ }^{59}$ Bruce

${ }^{54}$ F.F. Bruce, The Epistle to the Galatians: The New International Greek Testament Commentary, 82.

55Warren. W. Wiersbe, Merdeka Di Dalam Kristus: Tafsiran Surat Galatia (Bandung: Kalam Hidup, 2018), 13. 38.

${ }^{56}$ J.J.W Gunning, Tafsiran Alkitab: Surat Galatia (Jakarta: BPK Gunung Mulia, 2000),

${ }^{57}$ William Barclay, Memahami Alkitab Setiap Hari: Galatia Ephesus (Jakarta: BPK Gunung Mulia, 1996), 9.

${ }^{58}$ Barclay, 10.

${ }^{59}$ Barclay, 19. 
Chilton mengatakan bahwa orang Israel yang sudah percaya melihat Yesus sebagai penggenapan perjanjian Allah dengan bangsa Israel, sehingga mereka menuntut agar semua orang Kristen baik Yahudi maupun bukan, mempunyai tanda perjanjian itu, tetapi Paulus tidak sependapat dengan mereka. ${ }^{60}$ Paulus menjelaskan bahwa Abraham, bapa leluhur mereka, dibenarkan karena Abraham percaya akan janji, bahwa semua bangsa akan diberkati melalui dia (Gal. 3:6-9; bdk. Kej. 12:3; 15:6) dan janji berkat bagi semua bangsa digenapi dalam Kristus (Gal. 3:16), sehingga setiap orang percaya menerima janji itu. ${ }^{61}$

Hakh mengatakan bahwa orang-orang yang disebut "saudara-saudara palsu" (Gal. 2:4,5) mereka tidak membangkang atas Injil yang diberitakan Paulus, mereka hanya mau "menyempurnakan" apa yang Paulus telah sampaikan. Kekurangan Paulus adalah membawa jemaat Galatia kepada suatu status sebagai anak-anak Allah di dalam Kristus dan hanya bergantung kepada iman saja. Para saudara palsu ingin meyakinkan jemaat bahwa Kristus adalah Mesias yang telah dijanjikan oleh Allah untuk umat Israel sebagai anak Abraham. Taurat dan Kristus menurut guru palsu saling terkait, karena hanya di dalam lingkungan hukum Taurat janji itu dipenuhi dalam Kristus. Oleh karena itu, setiap orang harus melakukan hukum Taurat dan masuk menjadi anggota umat Yahudi. ${ }^{62}$ Jadi, hukum Taurat menurut para saudara palsu memiliki makna dan menjamin partisipasi orang Kristen secara penuh, inilah yang Paulus lihat sebagai tindakan mengacaukan dan memutarbalikkan Injil Kristus.

Kata "nomos" yang dipakai dalam surat Galatia, menurut terjemahan Lembaga Alkitab Indonesia (LAI) diartikan sebagai "hukum Taurat", terjemahan BIS diartikan sebagai "hukum Agama", terjemahan King James Version (KJV) dan New International Version (NIV) mengartikan sebagai "law" atau "hukum". Sutanto, mengartikan "nomos" sebagai hukum; kaidah; peraturan; hukum Taurat; kitab Taurat; Alkitab. ${ }^{63}$ Tafsiran lain juga mengartikan "nomos" sebagai hukum, undang-undang, kebiasaan yang menjadi standar keadilan yang ditetapkan oleh suatu negara. ${ }^{64}$ Secara umum 2004), 64.

${ }^{60}$ Bruce. Chilton, Studi Perjanjian Baru Bagi Pemula (Jakarta: BPK Gunung Mulia,

${ }^{61}$ Chilton, 67.

${ }^{62}$ Hakh, Perjanjian Baru: Sejarah Pengantar Dan Pokok-Pokok Teologisnya, 176.

${ }^{63}$ Hasan Sutanto, Perjanjian Baru Interlinear Yunani-Indonesia Dan Konkordansi Perjanjian Baru (Jakarta: LAI, 2019), 506.

64"Nomos," n.d., https://www.blueletterbibble.org/lang/lexion/lexion.cfm? Strongs $=\mathrm{G} 3551 \& \mathrm{t}=\mathrm{KJV}$. 
dalam Perjanjian Baru LAI menerjemahkan pemakaian "nomos", untuk hukum Kristus (Gal. 6:2), hukum iman (Rm. 3:27), hukum pikiran (Rm. 7:23), hukum dosa (Rm. 7:23), hukum kebebasan (Yak. 1:25; 2:12). Menurut Ladd, istilah "nomos" tidak sama dengan Torah Ibrani. Nomos pada dasarnya adalah "adat", kemudian berkembang dengan apa yang disebut dengan "hukum" dan sudut pandangnya bersifat manusiawi. ${ }^{65}$ Sedangkan Torah berarti petunjuk dan digunakan bukan hanya sebagai undang-undang yang telah diberikan Allah untuk ditaati, melainkan juga merupakan petunjuk ajaran ilahi. Dalam arti yang luas Torah menunjukkan wahyu ilahi secara keseluruhan. ${ }^{66}$ Menurut Agus Santoso, dalam konteks Galatia yang disebut sebagai Taurat bagi orang Yahudi bukanlah hanya kitab Pentateukh atau Perjanjian Lama, melainkan juga hukum-hukum Yahudi yang disebut sebagai Halakha. ${ }^{67}$

Jadi, kata nomos dalam surat Galatia tidak bisa diterjemahkan langsung sebagai "hukum Taurat" (terjemahan LAI), atau sama dengan Torah Ibrani. Tetapi sesuai dengan konteksnya, dapat diartikan sebagai hukum, peraturan-peraturan, adat istiadat Yahudi, yang didasarkan pada pemahaman mereka terhadap Perjanjian Lama. Namun, dalam surat Galatia ada kelompok tertentu yang mengajarkan nomos sebagai aturan adat istiadat yang ditambahkan dan harus dilakukan jemaat Galatia untuk menerima keselamatan yang sempurna dari Allah. Inilah yang disebut Paulus sebagai "Injil yang lain".

\section{KESIMPULAN}

Jadi, dalam Galatia 1:6-7, Paulus menjelaskan bahwa Injil adalah kasih karunia Kristus. Allah yang sendiri yang berinisiatif memanggil orangorang untuk percaya kepada Kristus. Inti dari pada Injil adalah berita tentang Kristus, yang adalah Allah sendiri telah datang ke dunia, mati untuk mengorbankan diri-Nya sebagai tebusan atas dosa manusia, sehingga setiap orang yang telah dipanggil dan percaya kepada-Nya memperoleh keselamatan yang sempurna. Paulus melihat bahwa keselamatan melalui kasih karunia inilah yang sedang ditinggalkan oleh orang-orang Kristen

${ }^{65}$ George Eldon Ladd, Teologi Perjanjian Baru: Jilid I \& II (Bandung: Kalam Hidup, 2017), 265.

${ }^{66}$ Ladd, 280.

${ }^{67}$ Santoso, Dia Menebus,Supaya Kita Diterima, Menjadi Anak: Tafsiran Surat Paulus Kepada Jemaat Di Galatia, 11. 
Galatia dan sedang menerima ajaran yang berbeda yang Paulus sebut sebagai "Injil lain".

Heteros euanggelion adalah ajaran yang bukan, atau sangat berbeda dengan Injil Kristus. Jika dilihat dari konteksnya, ditemukan bahwa ajaran mengenai Injil yang lain dalam surat Galatia menekankan kepada orang Kristen non-Yahudi untuk melakukan adat istiadat Yahudi yang disebut dengan Halakha. Paulus dalam surat Galatia menyebutnya sebagai nomos (hukum) yang menjadi suatu kewajiban yang harus dilakukan bagi orang Yahudi. Dalam peraturan tersebut, hal-hal yang wajib dilakukan seperti sunat, hari-hari tertentu dan peraturan-peraturan lainnya dengan tujuan untuk memperoleh kesempurnaan dihadapan Allah agar bisa diselamatkan.

Injil yang lain merupakan suatu ajaran yang mengacaukan dan ingin mengubah Injil Kristus dengan mengajarkan bahwa iman di dalam Kristus tidak sempurna dan harus ditambahkan dengan melakukan aturan adat istiadat Yahudi seperti sunat, untuk memperoleh keselamatan yang sempurna. Sehingga dalam surat Galatia sendiri Paulus menjelaskan bahwa keselamatan itu satu-satunya hanya melalui kasih karunia yang diperoleh melalui iman kepada Yesus Kristus. Allah yang memanggil setiap orang percaya untuk memperoleh keselamatan itu melalui karya Kristus. Implikasinya keselamatan melalui kasih karunia Kristus tidak perlu ditambahkan oleh usaha manusia atau dengan melakukan hukum Taurat.

\section{DAFTAR PUSTAKA}

Barclay, William. Memahami Alkitab Setiap Hari: Galatia Ephesus. Jakarta: BPK Gunung Mulia, 1996.

Barker, Kenneth L, and John R. Kohlenbergerr III. The Expositor's Bible Commentary: Abridged Edition New Testament. Grand Rapids: Zondervan, 1994.

Carson, D. A. Tafsiran Alkitab Abad Ke-21, 3, Matius-Wabyu. Jakarta: Yayasan Komunikasi Bina Kasih, 2017.

Chia, Philip Suciadi. Memahami Kitab-Kitab Perjanjian Lama Di Dalam Perjanjian Baru. Yogyakarta: Stiletto Indie Book, n.d.

Chilton, Bruce. Studi Perjanjian Baru Bagi Pemula. Jakarta: BPK Gunung Mulia, 2004.

Drane, John. Memahami Perjanjian Baru. Jakarta: BPK Gunung Mulia, 2005.

F.F. Bruce. The Epistle to the Galatians: The New International Greek Testament 
Commentary. Grand Rapids: Eerdmans, 2013.

Gunawan, Chandra. "Ketegangan Hubungan Yahudi Dan Bukan Yahudi Dalam Yudaisme Bait Allah Kedua Dan Dalam Surat Galatia." Veritas, Jurnal Teologi Dan Pelayanan, 2011. http://repository.seabs.ac.id/handle/123456789/226.

Gunning, J.J.W. Tafsiran Alkitab: Surat Galatia. Jakarta: BPK Gunung Mulia, 2000.

Hakh, Samuel Benyamin. Perjanjian Baru: Sejarah Pengantar Dan Pokok-Pokok Teologisnya. Bandung: Bina Media Informasi, 2010.

Hendriksen, William. New Testament Commentary: Galatians, Ephesians, Philippians, Colossians, and Philemon. Grand Rapids: Inter Varsity Press, 2007.

J.I, Packer. Dunia Perjanjian Baru. Malang: Gandum Mas, 1995.

L., Helen Miehle. Pedoman Penafsiran Alkitab: Surat Paulus Kepada Jemaat Di Galatia. Jakarta: LAI, 2011.

Ladd, George Eldon. Teologi Perjanjian Baru: Jilid I \& II. Bandung: Kalam Hidup, 2017.

Linebaugh, Jonathan. "The Grammar of the Gospel: Justification as a Theological Criterion in the Reformation and in Paul's Letter to the Galatians." Scottish Journal of Theology 71, no. 3 (August 14, 2018): 287-307. https://doi.org/10.1017/S0036930618000339.

Longman, Tremper, and David E. Garland. The Expositor's Bible Commentary: Roman-Galatians. Grand Rapids: Zondervan, 2005.

McConville, Gordon J. Sejarah Alkitab," in Tafsiran Alkitab Abad Ke 21: 3 Matius-Wabyu. Edited by D.A Carson. Jakarta: Yayasan Komunikasi Bina Kasih, 2017.

Moo, Douglas. J. Galatians. Grand Rapids: Backer, 2013.

Nggadas, Deky Hidnas Yan. Tafsiran Alkitab: Injil Matius Pasal 1-22. Jakarta: BPK Gunung Mulia, 2003.

"Nomos," n.d. https://www.blueletterbibble.org/lang/lexion/lexion.cfm? Strongs $=\mathrm{G} 3551 \& \mathrm{t}=\mathrm{KJV}$.

Santoso, Agus. Dia Menebus,Supaya Kita Diterima, Menjadi Anak: Tafsiran 
Surat Paulus Kepada Jemaat Di Galatia. Bandung: Bina Media Informasi, 2011.

Sihombing, Aeron Frior. "Pemikiran Teologi Deuteronomis." TE DEUM Jurnal Teologi Dan Pengembangan Pelayanan) 9, no. 1 (December 20, 2019): 1-32. https://doi.org/10.51828/td.v9i1.10.

_. "Pendidikan Karakter Dalam Khotbah Di Bukit." Regula Fidei: Jurnal Pendidikan Agama Kristen 4, no. 1 (2019): 39.

_. "Relasi Etika Perjanjian Lama Dengan Etika Global Hans Kung." TE DEUM (Jurnal Teologi Dan Pengembangan Pelayanan) 4, no. 2 (April 12, 2021): 163-92. https://doi.org/10.51828/td.v4i2.61.

Silalahi, Haposan. "Historical Grammatical: Sebuah Metode Hermeneutik Dalam Menemukan Makna Yang Tersembunyi Dalam Teks-Teks Alkitab." Te Deum 8, no. 1 (2018).

Sunarto. "Integritas Seorang Pengkhotbah Dan Kualitas Khotbah Dalam Pemberitaan Firman Tuhan." TE DEUM Jurnal Teologi Dan Pengembangan Pelayanan) 7, no. 1 (April 27, 2021): 77-99. https://doi.org/10.51828/td.v7i1.103.

Sutanto, Hasan. Perjanjian Baru Interlinear Yunani-Indonesia Dan Konkordansi Perjanjian Baru. Jakarta: LAI, 2019.

Tampubolon, Yohanes Hasiholan. "Kontekstualisasi Metodologi Misiologi Paulus Dalam Dunia Kontemporer." Excelsis Deo: Jurnal Teologi, Misiologi, Dan Pendidikan 3, no. 2 (December 31, 2019): 13-25. https://doi.org/10.51730/ed.v3i2.13.

. "Misi Gereja Di Era Kapitalisme Global: Eksplorasi Pelayanan Misi Yesus." Societas Dei: Jurnal Agama Dan Masyarakat 7, no. 2 (October 19, 2020): 197-217. https://doi.org/10.33550/sd.v7i2.137.

Tampubolon, Yohanes Hasiholan, Aeron Frior Sihombing, Geri Gehotman Mangasake, Hafa' Akhododo, Maria Mayda Bunge Tana, Ricky Pianto Randa, and Williams Jefferson Bill Walimena. "Analisis Perbandingan Gramatikal-Historis Bahasa Lidah Dalam 1 Korintus Dan Kisah Para Rasul.” Jurnal Teologi Berita Hidup 3, no. 2 (March 25, 2021): 189-204. https://doi.org/10.38189/jtbh.v3i2.80.

Tenney, Merrill C. Survei Perjanjian Baru. Malang: Gandum Mas, 2009.

Wiersbe, Warren. W. Merdeka Di Dalam Kristus: Tafsiran Surat Galatia. 
Bandung: Kalam Hidup, 2018.

Wong, Pater S. Injil Yesus Kristus: Sebuah Pengantar Teologi Injili. Jakarta: Yayasan Kartidaya, 2011.

Yahya, Pancha W. "Sebuah Kritik Terhadap Pandangan James D. G. Dunn Tentang 'Melakukan Hukum Taurat' Dalam Galatia 2:16 ." Veritas : Jurnal Teologi Dan Pelayanan 14, no. 1 (April 1, 2013): 107-26. https://doi.org/10.36421/veritas.v14i1.270.

ROBI PRIANTO, adalah dosen teologi di STT SAPPI Ciranjang. Beliau menyelesaikan program Sarjana Teologi di STT SAPPI Ciranjang dan Magister Teologi di STT Cipanas.

KEZIA LAWIRA, adalah dosen teologi di STT SAPPI Ciranjang dan juga pelayanan di Gkim Hosana, Bandung. Beliau lulus Sarjana Teologi dari STT SAAT, Malang, dan Magister Pendidikan dari Sekolah Tinggi Alkitab Nusantara, Malang.

NOVIANTO, merupakan mahasiswa program Sarjana Teologi di STT SAPPI dan sedang menyelesaikan praktik pelayanan satu tahun. 